\title{
Lídia Jorge e o romance português da segunda metade do século XX
}

\author{
Débora Leite David \\ Universidade de São Paulo
}

\begin{abstract}
RESUMO: DEPOIS DE UM PERÍODO QUE PODERÍAMOS CHAMAR DE TRANSIÇÃO ENTRE A DÉCADA DE 1950 E O PÓS-25 DE ABRIL, O INÍCIO DA DÉCADA DE 1980 VISLUMBRA AUTORES E, PRINCIPALMENTE, AUTORAS MAIS AUDACIOSAS E MADURAS QUE PROJETAM EM SUAS ESCRITAS UMA OUTRA PERCEPÇÃO DA REALIDADE DE PORTUGAL COM O PIONEIRISMO DE NOVAS SOLUÇÕES LITERÁRIAS. A RECUSA À ALIENAÇÃO E À APATIA HERDADAS DO SALAZARISMO PROMOVE A REVISÃO DESSE PROCESSO SOCIOCULTURAL POR MEIO DAS IMAGENS ONÍRICAS E DA ALEGORIA QUE, A PARTIR DE ENTÃO, SÃO ENCONTRADAS NOS ROMANCES PORTUGUESES.
\end{abstract}

ABSTRACT: AFTER A PERIOD OF WHAT WE MIGHT CALL TRANSITION BETWEEN THE 1950S AND THE AFTERMATH OF APRIL 25 ${ }^{\text {TH }}$ 1974, THE BEGINNING OF THE $1980 \mathrm{~S}$ SEES THE EMERGENCE OF A NEW SET OF BOLDER, MORE MATURE PORTUGUESE AUTHORS, FOR THE MOST PART WOMEN. THEIR WRITING EXPOUNDS A NEW PERCEPTION OF PORTUGUESE REALITY AND PIONEERS NEW LITERARY SOLUTIONS. IT REFUSES THE ALIENATION AND APATHY OF THE SALAZAR YEARS AND PROMOTES THE REEVALUATION OF ITS SOCIO-CULTURAL DYNAMIC VIA DREAM IMAGES AND ALLEGORY, WHICH, FROM THEN ON, ARE TO BE FOUND IN PORTUGUESE NOVELS.

PALAVRAS-CHAVE: LÍDIA JORGE, ROMANCE, LITERATURA PORTUGUESA, FICÇÃO/ HISTÓRIA.

KEYWORDS: LÍDIA JORGE, NOVEL, PORTUGUESE LITERATURE, FICTION/HISTORY. 
romance português na segunda metade do século XX se sobressai às outras literaturas europeias, como a francesa, a espanhola, a inglesa ou a italiana, também em razão de um verdadeiro boom de autoras que foram capazes de imprimir uma marca própria ao cânone da literatura portuguesa daquele período. Não obstante o fato de os artistas em geral serem inveterados consumidores de seus pares, as escritoras portuguesas que surgem a partir de então empreendem uma incursão criativa que ultrapassa o limiar do saudosismo ingênuo ou mesmo de uma mera imitação artística. A ficção portuguesa desse período, nesse sentido, segue os passos da poesia do mesmo período ao promover uma espécie de hora zero de si mesma, como afirma Eduardo Lourenço (LOURENÇO, 2001, p. 92-94). Após um período que poderíamos chamar de transição entre a década de 1950 e o pós-25 de Abril, o início da década de 1980 vislumbra autores e, principalmente, autoras mais audaciosas e maduras que projetam em suas escritas uma nova percepção da realidade de seu país com o pioneirismo de novas soluções literárias. Parece-nos um exemplo por excelência Maria Gabriela Llansol, cuja produção literária não se curva às nomenclaturas de gênero como conto, romance, etc. Ainda que seja possível identificar ali elementos tradicionais da narrativa suas obras são verdadeiros quadros de experimentação e de ensimesmamento, o que as aproximam, por vezes, de formas mais palatáveis aos leitores, como o diário, por exemplo.

Origina-se, deste modo, ao longo da segunda metade do século XX, e fortemente a partir da década de 1980, uma ficção portuguesa que promove uma nova representação do imaginário coletivo português, silenciado e ainda sob o jugo do fantasma da ideologia salazarista. Se tomarmos as obras publicadas de autoras portuguesas, de Agustina Bessa-Luís a Maria Gabriela Llansol, podemos dizer que a ficção portuguesa contemporânea desviou-se do Neorrealismo em todas as suas formas, revisitando a História Portuguesa pelo viés da marginalidade e da pluralidade.

É a partir de A sibila, romance de Agustina Bessa-Luís, publicado em 1954, que, segundo Eduardo Lourenço, é notada "uma espécie de sonho minucioso a propósito do real e um realismo não menos minucioso do lado onírico da vida" (LOURENÇO, 2001, p. 92), os quais se alastram e permeiam a literatura portuguesa contemporânea. Há, inclusive, considerações críticas a respeito da constituição naquele momento de uma corrente literária que se conformaria a certo "realismo mágico" nos moldes da literatura da América 
Latina. Algumas características das obras permitiriam esse tipo de reflexão como, por exemplo, a inconsciência cultural, a ancestralidade mítica ou ainda as mitologias do novo mundo que se derramam em solo lusitano, insufladas pelo american way of life, a queda de Salazar e a abertura do país para o cenário político e cultural internacional. Nessa seara, é emblemático o romance Cais das merendas (1982), de Lídia Jorge, que descreve o sul de Portugal oscilante entre o ser português ancestral e as novas formas de estar no mundo.

Assim, é possível afirmar que ocorreu ao longo do século XX uma espécie de transmutação na literatura portuguesa, que partiu de um radicalismo do neorrealismo denominado por Eduardo Lourenço de "foclorismo naturalista", e de conflitos existenciais do indivíduo perante Deus e a sociedade, como vemos em José Régio, por exemplo, até chegar a esse pseudo "realismo mágico", de inspiração latino-americana, que revisita a história portuguesa de um modo onírico. Ressalvadas as possíveis rotulações desse momento histórico-literário em Portugal, é de notar a presença e a importância da alegoria como figura de estilo nessa produção romanesca, resultando na ampliação do viés mítico, fazendo com que a narrativa realista se socorra do imaginário para tentar resolver as questões do novo ser português que se vislumbra com a descolonização da África portuguesa.

Interessa-nos, sobretudo, a acepção que Walter Benjamin adotou de alegoria como a revelação de uma verdade oculta. Desse modo, a alegoria não representaria a realidade como de fato é, mas sim apresentaria ao leitor uma versão de como foi ou de como poderia ser essa realidade. A partir da máxima de que "as alegorias são no reino dos pensamentos o que são as ruínas no reino das coisas" (BENJAMIN, 1984, p. 200), o filósofo alemão coloca a alegoria como expressão da melancolia. Tais ruínas, como fragmentos que são, abrigam em si a história de um indivíduo ou de um povo, porém, como um enigma que necessita ser decifrado. Esses fragmentos são responsáveis pelas distorções que observamos na historiografia da obra de arte, e que podem ser estendidas à forma e à linguagem. Dessas distorções, temos o caráter ambivalente do olhar melancólico sobre o mundo exterior que tentamos contar, representar, dizer. É na poesia de Charles Baudelaire que Benjamin aponta a

1. Referimo-nos ao romance Jogo da cabra cega (1934) de José Régio. 
expressão do esfacelamento do indivíduo representado pelo spleen, ${ }^{2}$ ou o tédio na vida moderna. A melancolia, pois, nada mais é do que a imagem da catástrofe continuada na marcha da civilização. Na representação dessa catástrofe, dos fragmentos que compõem essa realidade, temos a alegoria moderna que serve à representação da degenerescência e da alienação humanas.

Ainda refletindo acerca da tese de Walter Benjamin em que o "Anjo da História" se volta ao passado, mas é lançado ao futuro, temos um campo de dualismos. Ao mesmo tempo em que esse Anjo contempla a catástrofe, recebe o sopro do paraíso, vê ruínas de um lado, mas também presencia o progresso de outro. Uma série de duplos que têm o condão de caracterizar um contexto histórico permeado pela relatividade dos valores e pela precariedade. É de notar que essa relatividade mina inclusive o tempo que, na contemplação melancólica, se estende até o presente e alcança o futuro, o que implica dizer que a catástrofe não se restringe ao tempo passado, continua no presente e é lançada para o futuro. A História não é construída no tempo vazio e possui raízes que se espalham por todos esses momentos.

Com essa perspectiva é possível refletir sobre a função da alegoria, especialmente quanto à representação literária, e que parece propor a imagem fragmentada e inacabada, destacando o momento em detrimento da totalidade e buscando recuperar a continuidade na própria desarticulação e heterogeneidade desses fragmentos. A alegoria seria, então, a representação de fragmentos do passado, da História e da catástrofe, propagando a voz do oprimido ao relevar aquilo que está implícito no discurso hegemônico. A sua decifração demandaria o recurso da intertextualidade para que fosse possível abstrair uma nova leitura e com ela outro sentido mais profundo.

A alegoria mantém uma afinidade com as formas simples, como a parábola a fábula e o conto - na ambiguidade de uma narrativa que oscila entre o caráter enigmático e o exemplar, e remete à ficcionalização da ancestralidade, Essa dinâmica narrativa apresentou-se de maneira arraigada, sobretudo, entre a produção literária portuguesa do pós-25 de Abril, tornando possível a ficcionalização de questões ligadas à identidade portuguesa e ao respec-

2. Termo popularizado pelo poeta Charles-Pierre Baudelaire (1821-1867), surgiu na literatura durante o período do Romantismo. Significava uma extrema melancolia acompanhada do desejo de autodestruição. A morte era considerada a solução e o caminho para o alívio das angústias do indivíduo. 
tivo imaginário coletivo por meio da problematização do passado recente do Império Português. Seria na autoria feminina da literatura portuguesa da segunda metade do século XX que veríamos a realidade desconstruída por um profundo onirismo que converteria silêncio em palavras ou desvendaria os enigmas do silêncio. Autoras como Maria Isabel Barreno (De noite as árvores são negras, 1968) ou Maria Velho da Costa (Maina Mendes, 1969) faziam eco ao nowveau roman, ${ }^{3}$ porém não respeitavam completamente ao antiobjetivismo e ao antilirismo que o caracterizava. Mesmo assim trabalhavam com a materialidade da escrita e com numerosas inovações formais e textuais, como também usavam em seus romances a imaginação e sua desconstrução para representar a realidade.

É possível dizer que esse processo teve seu início a partir da década de 1950, quando surgiram escritores das mais diversas tendências no cenário literário português como Carlos de Oliveira, José Cardoso Pires, Fernanda Botelho ou David Mourão-Ferreira. Com a publicação de $A$ Sibila, em 1954, por Agustina Bessa-Luís, a narrativa contemporânea portuguesa conhece uma escrita cuja originalidade recusa influências estético-ideológicas e assume a libertação do imaginário. A narrativa, então, será construída com a dissecação das paixões humanas que se desfiam pelo viés mítico do espaço, do tempo e das personagens. A subversão total do cânone tradicional, no entanto, vem no início da década de 1960, quando conhecemos os autores que consolidam essas mudanças na narrativa contemporânea e se aproximam mais dos postulados do nouveau roman. $\mathrm{O}$ experimentalismo e a inclinação para radicalizar a desconstrução dos elementos narrativos permeiam obras como Os pregos na erva (1962), de Maria Gabriela Llansol, A paixão (1965), de Almeida Faria, $O$ mestre (1963), de Ana Hartely, Os passos em volta (1963), de Herberto Helder, ou Maina Mendes (1969), de Maria Velho da Costa. A partir de então, a narrativa contemporânea portuguesa apresentará como traço generalizado propostas como: o uso da metalinguagem; a fragmentação do texto; a utilização simultânea de variados gêneros; a redução da pontuação; o entrelaçamento propo-

3. Nouveau Roman é uma denominação que se aplicou a um conjunto de romances franceses publicados pela editora Éditions de Minuit após a Segunda Guerra Mundial. Essas obras da autoria de Alain Robbe Grillet, Nathalie Sarraute, Michel Butor, Marguerite Duras e Claude Simon, representaram uma renovação da forma romanesca com a rejeição de características do romance tradicional. Tropismes (1938), de Nathalie Sarraute, é considerado o primeiro romance desse movimento. 
sital entre autor, narrador e personagem; o uso de múltiplas vozes narrativas; entre outras.

Um traço importante é o tratamento diferenciado dado aos elementos da narrativa como o tempo e o espaço. O tempo apresenta-se comumente fragmentado, de modo que as várias dimensões do tempo se confundam e possibilite a sensação de relatividade da sucessão dos acontecimentos. Assim, temos a quebra do tempo linear e a sua distorção com a mescla do presente, do passado e do futuro, comprometendo inclusive a inteligibilidade da duração da narrativa ficcional. O espaço, por sua vez, poucas vezes é determinado explicitamente. Essa inclinação implica a escassez de referências, fazendo do espaço ficcional apenas um pano de fundo à narrativa, ou, por vezes, um espaço relativizado pelo apagamento de sua existência ou de suas características físicas. Essas estratégias possibilitam a conciliação de conceitos e figuras que jamais poderiam juntar-se na mesma narrativa. O mágico e o histórico ou o conhecimento e o desejo são exemplos possíveis dessa apresentação simultânea e problemática, que permite o diálogo crítico entre a realidade e a irrealidade. Assim, o leitor tem diante de si a possibilidade da coexistência de figuras reais e irreais ou de personagens históricas e ficcionais interagindo no mesmo espaço/tempo ficcional. Elabora uma apreensão múltipla da realidade, cuja dinâmica revela um processo de questionamento da presença portuguesa na África, da identidade portuguesa pós-25 de Abril e do futuro possível daquele país.

Se o nouveau roman é um romance de ruptura, que destrói os modelos essencialistas do romance burguês e apresenta ao leitor valores mutáveis e o questionamento de um mundo conhecido, é também possível aproximarmos a essa perspectiva os romances da literatura portuguesa desse momento. Romances como O dia dos prodígios, de Lídia Jorge (1980), por exemplo, ${ }^{4}$ sua obra de estreia, que recusa a alienação e a apatia herdadas do Salazarismo e propõe uma revisão desse processo sociocultural por meio das imagens oníricas e da alegoria, poderiam ser exemplos de experimentações que são próprias do nouveau roman, notadamente pela inovação na sua forma. Longe de causar estra-

4. Nesse viés também podemos incluir obras como as de Olga Gonçalves (Este verão o emigrante là-bas, 1978) e Maria Gabriela Llansol (Trilogia “Geografia dos Rebeldes": O livro das comunidades, 1977; A restante vida, 1983; e Na casa de Julho e Agosto, 1984). 
nheza, o romance foi recebido com calorosa aceitação e a escritora apontada como uma das mais importantes revelações da literatura portuguesa, justamente em razão da sua postura inovadora e renovadora do universo literário de Portugal. Construído como uma alegoria de um Portugal isolacionista e estagnado, $O$ dia dos prodígios representa criticamente o ser português que está sempre à espera de alguma transformação que venha de fora. Trata-se da história de Vilamaninhos, uma comunidade ao Sul de Portugal, completamente isolada e ignorante sobre as mudanças promovidas pela revolução. $\mathrm{Na}$ tensão que existe entre o mundo exterior, representado por soldados revolucionários, e o mundo rural, reservado e mágico de Vilamaninhos, as personagens vivem suas pequenas histórias e mostram em seu comportamento coletivo uma síntese da identidade portuguesa.

A estrutura narrativa desse romance apresenta uma forma inovadora na separação espacial das falas das personagens e da narração, implicando um viés experimentalista que poderia aproximá-lo do nouveau roman e do estruturalismo. No entanto, a sua dimensão mítico-metafórica na representação da realidade e a naturalização do insólito o deslocam para o universo do realismo mágico. Uma estratégia narrativa em que a representação da realidade abrange duas visões opostas - a natural e a sobrenatural, mediadas pelo mito. Dessa forma, Lídia Jorge reforça o valor metafórico da literatura portuguesa no sentido de incitar o questionamento sobre a identidade lusitana e seu contexto sociocultural, na forma como eram fomentados durante a ditadura salazarista no aperfeiçoamento da máquina colonialista.

Outra questão de relevância para a literatura portuguesa desses anos, compartilhada com outras literaturas, é a ficcionalização da História. A influência da tradição narrativa do passado e a interação entre a História e a ficção são elementos que estão presentes na literatura desse período. Em relação à obra de Lídia Jorge, isso aparece fortemente em romances como $A$ costa dos murmúrios e $O$ dia dos prodígios. Aqui não se trata de lidar com os postulados do romance histórico tradicional, ${ }^{5}$ como propõe Walter Scott, em que a legitimidade do mundo ficcional no resgate do passado histórico implica a reconstituição ficcional de personagens e fatos históricos, e, por isso,

5. Surge no início do século XIX (Romantismo). Dentre os numerosos romances destacamos Ivanhoé, de Walter Scott, Eurico, o Presbitero, de Alexandre Herculano e Guerra e Pa\%, de Tolstói. 
uma aproximação entre a História e a ficção mediada ora pela veracidade, ora pela verossimilhança. Coloca-se aqui a questão de metaficção historiográfica, como na acepção de Linda Huntcheon, em que a problematização entre História e ficção prima pelo caráter reflexivo, apropriando-se de acontecimentos e personagens históricas (HUNTCHEON, 1991). Nessa apropriação, o romance apresentaria uma representação que subverte os acontecimentos e os valores, promovendo o questionamento desse passado revisitado.

Nesse sentido, lembramos a forma como a personagem Eva Lopo, em $A$ costa dos murmúrios, se refere, ironicamente, à História: "Acho até interessante a pretensão da História, ela é um jogo muito mais útil e complexo do que as cartas de jogar" (JORGE, 2004, p. 42). Assim como a ficção, a História é incapaz de representar o passado na sua totalidade e na sua intensidade. A representação da realidade seria sempre uma tentativa incompleta que se constrói na seleção de fatos reduzida a um único ponto de vista, que limita inexoravelmente a representação dos acontecimentos vivenciados.

A costa dos murmúrios parece uma memória daquilo que foi vivenciado, porém extirpado da grande história. O romance se contrapõe à história unilateral e hegemônica, que aniquila quaisquer outras versões e, por isso, quaisquer vestígios das vítimas e do sacrifício humano que possam ser encontrados entre os seus escombros. Esse passado recuperado, ainda que em uma pequena parcela, propõe revolver os acontecimentos que se queriam enterrados, mas que continuam desde então a assombrar o imaginário coletivo português. Podemos dizer que esse romance de Lídia Jorge resgata a possibilidade de se elaborar reflexões necessárias sobre a Guerra Colonial.

O romance de Lídia Jorge incita a provocação, tendo em vista que Portugal vivenciava o fim de sua experiência imperial sem traço algum de traumatismo histórico e cultural, como afirma Eduardo Lourenço. Essa apatia coletiva que sucedeu acontecimentos tão traumáticos e relevantes no cenário internacional, como a Guerra Colonial, principalmente no início da década de 1970, com o massacre de Wiriyamu em Moçambique, parece demonstrar como a imagem mítica da identidade portuguesa não residia no vínculo que a nação portuguesa teria com os seus territórios ultramarinos, como afirmava o discurso salazarista, mas sim no seu papel messiânico e civilizador. Tornava-se, desse modo, questionável a aprovação dos motivos da presença portuguesa na África, bem como da guerra que buscava sustentá-la a qualquer custo. Essa 
aprovação, em realidade, era uma determinação do regime salazarista que manipulava a opinião pública nacional e, em certa medida, a internacional. $\mathrm{O}$ luto da perda dos territórios ultramarinos foi experimentado com tranquilidade, quase indiferença, o que denotaria inconsciência sobre as razões políticoeconômicas que fundamentariam a manutenção do Império Português, ou pior, o afastamento da responsabilidade pelo insuficiente conhecimento dos fatos e suas implicações. Tais posturas demonstram igualmente a alienação em que o país se encontrava e que explicaria a tolerância em relação ao poder ditatorial e seu discurso, que buscava legitimar a defesa militar dos territórios africanos. A empresa colonial, assim, dizia respeito mais ao regime salazarista, do que à nação portuguesa.

A costa dos murmúrios, nesse passo, assim como outros romances do mesmo período, ocupou-se de questionar o passado recente, especialmente em relação à consciência popular, que o ignorava ou o conhecia vagamente. Do contrário, o total silêncio e o permanente esquecimento manteriam na ignorância o verdadeiro ser português e, consequentemente, sua incapacidade de construir um devir histórico. Nesse esforço que se empreende no campo intelectual, a voz que não é mais silenciada impede que se rompa totalmente com o passado, e por consequência, inviabiliza sua repetição de forma incessante. Para superar esse passado é necessário cavar as lembranças, mesmo as piores, e expor as feridas, pois é a anamnese que pode levar os indivíduos a elaborar o seu luto (CHARLES, 2009, p. 100-104). A anamnese apresenta-se como forma de elaboração do luto, o que promove um processo catártico, substituindo o silêncio e a repressão que o acompanha por uma nova perspectiva de futuro. Promove, então, a consciência do indivíduo que vivenciou a catástrofe em relação à crise em que se encontra, bem como a possibilidade de sobrevivência qualitativa com a elaboração dessa experiência.

Nesse sentido, é notável a batalha que encontramos no romance de Lídia Jorge entre heroísmo e barbárie, realizada, especialmente, por meio do confronto entre a coragem da postura de herói do noivo Luís Alex e seu duplo Capitão Forza Leal, com seus atos de violência e intolerância sistematicamente colocados ao longo da narrativa. Mais do que representar uma singela denúncia da verdadeira dinâmica colonialista em Moçambique mascarada pelo regime salazarista, a autora promove o questionamento e a problematização da condição humana e da ética no contexto da guerra. 
O romance $A$ costa dos murmúrios foi construído de modo a encenar um universo fragmentado e precário, portanto, afastando-se da percepção de totalidade. Características como a fragmentação que deriva da marcada oralidade da narrativa através da personagem Eva Lopo e do esfacelamento temporal visto pelos desvãos da memória podem ser lidas como fatores que reforçam o sentido da obra que é a elaboração da Guerra Colonial no imaginário coletivo português. No entanto, a problematização da fronteira ética da condição humana se mostra como uma questão aberta. A resposta que é perseguida ao longo de toda a narrativa e que reside na autoria e responsabilidade pelo massacre do etanol é esclarecida e propicia um final conclusivo (JORGE, 2004, p. 111). ${ }^{6}$ Mas, o dilema apontado desde o início acerca da tênue lâmina que separa o heroísmo da barbárie, este não permite conclusão, mantendo-se como uma questão aberta à personagem protagonista e aos leitores, como explanado por Maria Manuela Cabral:

E nesta pluralidade de questões poderá residir a "abertura" a uma multiplicação de sentidos e a indeterminação. Assim, a morte que é tema do romance já não será apenas a de uma sociedade envolvida numa guerra pela cumplicidade da ditadura, ou a de qualquer sociedade ameaçada pela violência, mas também a ameaça de morte que paira actualmente sobre a esperança no claro discernimento entre valores tradicionalmente opostos e bem delimitados. (CABRAL, 1996, p. 136)

A revisitação do passado nada mais é do que revisitar o próprio presente. Nesse sentido, os romances escritos a partir da Revolução dos Cravos são cada vez mais enredados na revisitação do passado em favor da possibilidade de sua apropriação e desconstrução para a compreensão do presente. Para Eduardo Lourenço, trata-se da "expressão de um tempo" em que o realismo se exauriu e promoveu a fuga de uma cronologia empírica e de sua história de certezas, cujo exemplo mais destacado é José Saramago. Nas palavras de Eduardo Lourenço:

6. "A garrafa era um desses vasilhames de plástico vulgar de refrigerante a litro, rolhada a lata, a que tinham colocado um rótulo de vinho." 
Um presente que não é o que ele desejaria que fosse, se aqueles tempos onde enraízam as plurais mentiras que nos servem de verdade fossem iluminadas com a luz rasante, desmitificadora que o seu olhar irônico projeta sobre épocas, fatos, milagres, que nos impediram até hoje de habitar a nossa própria e nada transcendente casa. (LOURENÇO, 2001, p. 100-101)

Desta forma, na segunda metade do século XX, sobretudo entre as décadas de 1960 e 1980, os autores portugueses - e com eles Lídia Jorge - ultrapassam as fronteiras da temporalidade de uma memória fechada em si mesma, atribuindo uma função mítica às suas narrativas e situando-as em momentos oníricos que permitem o acesso a variados pontos da linha do tempo histórico. Como resultado, percebemos nessa deambulação temporal a revisitação do próprio presente e a sua consequente problematização. Numa espécie de inclinação antirrealista, esses autores privilegiam a alegoria, a lenda e o mito, e a mitopoética, apropriando-se ficcionalmente dessa identidade portuguesa para empreender a sua ressignificação, relativizando-a a partir das palavras silenciadas no discurso salazarista e da realidade ignorada pelo imaginário português.

\section{Referências Bibliográficas}

BENJAMIN, Walter. Origem do drama barroco alemão. São Paulo: Brasiliense, 1984.

BARRENO, Maria Isabel. De noite as árvores são negras. Lisboa: Europa-América, 1968. BESSA-LUÍS, Agustina. A sibila. Campinas (SP): Pontes, 2000.

CABRAL, Maria Manuela Afonso de Lacerda. A História como memória em A Costa dos Murmúrios, de Lidia Jorge. Apresentada como tese de doutorado paraLiteraturas Românicas Modernas e Contemporâneas,Faculdade de Letras, Universidade do Porto, Porto, 1996. 165 fls.

CHARLES, Sébastien. Cartas sobre a hipermodernidade ou o hipermoderno explicado às crianças. São Paulo: Barcarolla, 2009.

COSTA, Maria Velho da. Maina Mendes. Lisboa: Moraes, 1969.

FARIA, Almeida. A paixão. 3. ed. Lisboa: Planeta de Agostini, 2000.

HARTELY, Ana. O mestre. 2. ed. Lisboa: Moraes, 1976.

HELDER, Herberto. Os passos em volta: contos. 2. ed. Lisboa: Portugália, 1964.

HUNTCHEON, Linda. Poética do pós-modernismo. Rio de Janeiro: Imago, 1991. 
JORGE, Lídia. Cais das merendas. 6. ed. Lisboa: Dom Quixote, 2002. - A costa dos murmúrios. Rio de Janeiro: Record, 2004. . O dia dos prodígios. 4. ed. Mem Martins: Europa-América, 1982.

LLANSOL, Maria Gabriela. Os pregos na erva. 2. ed. Lisboa: Rolim, 1987.

LOURENÇO, Eduardo. A nau de Ícaro e Imagem e miragem da Lusofonia. São Paulo: Cia. das Letras, 2001. p. 92-94.

RÉGIO, José. Jogo da cabra cega. Porto: Brasília, 1982.

Recebido em 05/03/2011 e aprovado em 10/04/2011. 